\title{
A UNIVERSIDADE CONTEMPORÂNEA ENTRE DOIS CONSERVADORISMOS
}

\author{
Sylvia Gemignani Garcia ${ }^{1}$
}

\begin{abstract}
Resumo:
Este texto é a versão escrita de minha contribuição à mesa redonda intitulada "A educação no Brasil hoje", realizada no $46^{\circ}$ Encontro Nacional de Estudos Rurais e Urbanos do CERU, em homenagem ao centenário de Maria Isaura Pereira de Queiróz, ocorrido em junho de 2019. Ele articula certas análises de cunho sociológico para delinear o cenário político e cultural contemporâneo, no qual se enfrentam e cooperam entre si o conservadorismo progressista liberal, que há décadas promove a reforma organizacional da universidade, e o novo conservadorismo retrógrado da nova direita, com seus ataques à educação laica, ao pensamento crítico e à ciência. Detalhando alguns paradoxos da administração gestionária da produção e reprodução do conhecimento na universidade contemporânea, a reflexão relaciona as exigências de desempenho da visão conexionista dominante ao aumento do sofrimento mental entre estudantes universitários. Constrói-se, assim, uma leitura dos dois sistemas de dominação que se combinam na atualidade, ameaçando a continuidade histórica das instituições educacionais modernas e criando fortes obstáculos às perspectivas emancipatórias contra as quais se formaram.
\end{abstract}

Palavras-chave: Reforma organizacional da universidade. Sistemas de dominação. Capitalismo conexionista. Depressão.

\begin{abstract}
:
This text is the written version of my contribution to the round table "The education in Brazil today, held at the CERU National Meeting, in honor to the centenary of Maria Isaura Pereira de Queiroz, which took place in June 2019. He articulates certain analyzes of sociological nature to outline the political and cultural contemporary scenario, in which progressive liberal conservatism, that since decades promotes the organizational reform of the University, and the new backward conservatism from right wing, with its attacks on secular education, critical thinking and science. Detailing some paradoxes of management, that administer production and reproduction of knowledge in contemporary universities, reflection relates the performance requirements of the dominant connectionist view to the increasing mental suffering among university students. Thus, an reading of the two systems of domination that are currently combined, threatening the historical continuity of modern educational institutions and creating strong obstacles to the emancipatory perspectives against which they were formed.
\end{abstract}

Keywords: Organizational reform of university. Domination systems. Conexionist capitalism. Depression.

É muito significativo para mim fazer parte do Encontro Nacional do Centro de Estudos Rurais e Urbanos que celebra os 100 anos de sua fundadora e inspiradora, Maria Isaura Pereira

\footnotetext{
${ }^{1}$ Professora do Departamento de Sociologia da Faculdade de Filosofia, Letras e Ciências Humanas da USP. Email: sylgemig@usp.br
} 
de Queiroz. Foi sob a direção da Professora Maria Isaura que participei da minha primeira equipe de pesquisa, como aluna da graduação em Ciências Sociais, equipe na qual, entre outros trabalhos, realizamos um mapeamento das unidades de ensino e pesquisa da USP, que Maria Isaura intitulou, então, Retrato da USP aos 50 anos. Foi ali que comecei a conhecer a história da USP e a descobrir alguns problemas sociológicos suscitados pelo estudo das universidades públicas modernas, tema do qual nunca mais me afastei e que me foi ofertado, me foi apresentado, por Maria Isaura. É, portanto, com franco reconhecimento que me junto à equipe do CERU e suas convidadas e convidados nesta homenagem, ressaltando uma das várias modalidades de atuação acadêmica e intelectual de Maria Isaura Pereira de Queiroz, a Maria Isaura professora, orientadora, aquela que mostra, que apresenta, que faz ver, revelando e provocando o interesse pelo conhecimento.

E é justamente abordando o tema da universidade contemporânea que trago minha contribuição a este Encontro. Trata-se de um exercício de reflexão, com base em leituras e discussões $^{2}$ que, tendo por referência primeira a sociologia de Pierre Bourdieu, busca entender as questões da educação em sua articulação com a cultura, o conhecimento e o poder.

O primeiro movimento desta reflexão é enfrentar a pungência posta pelo título desta mesa, este hoje que nos interpela brutalmente como uma ameaça: ameaça de destruição da própria concepção de um sistema moderno de escolarização pública e universal, enquanto requisito básico de uma cultura política laica em uma sociedade pautada pelos valores da igualdade e da liberdade. Sistema que nunca se implantou plenamente e que se vê, hoje, acusado, ameaçado, desqualificado e em desmontagem, com base em uma visão ultraconservadora, anti-iluminista, antidemocrática, francamente misógina e racista, cujo antiintelectualismo difamatório evoca o terceiro lema da sociedade distópica descrita por Orwell em 1984: "ignorância é força”. Com um estilo cínico, de desprezo aberto pelos valores modernos da justiça, da verdade e da beleza, a nova visão conservadora se compraz na brutalidade, no escárnio e na mentira, encarnando a sombra do Iluminismo em sua recusa do conhecimento e em sua capitalização do ressentimento daqueles que, não tendo obtido conhecimento, não podem reconhecê-lo (ALEXANDER, 2018; BOURDIEU, 2007).

Nos termos dos modelos de sistemas de dominação que Luc Boltanski (2013) tem desenvolvido, visando entender a perda de potência social e política da crítica à ordem capitalista, pode-se associar a atuação do novo conservadorismo ao sistema de dominação pelo

\footnotetext{
${ }^{2}$ Discussões realizadas, principalmente, no âmbito do Grupo de Pesquisa de Sociologia da Educação, Cultura e Conhecimento, coordenado por mim e por Ana Paula Hey no Departamento de Sociologia da USP.
} 
terror, que se alimenta do medo promovido pelo uso da violência para a manutenção de profundas assimetrias sociais. Mas, para situar o contexto do qual ele emerge, é preciso considerar o conservadorismo progressista do sistema de dominação gestionária, que se desenvolveu historicamente a partir da segunda metade do século XX. Juntos eles delineiam o momento contemporâneo, situando os modos pelos quais, disputando entre si, se alimentam reciprocamente, em complexas combinações que podem criar obstáculos ainda mais fortes às perspectivas emancipatórias contra as quais se formaram.

Segundo Boltanski e Chiapello (2009), em sua investigação sobre as mudanças no modo de produção capitalista nas décadas de 1980 e 1990 na França, o espírito do novo capitalismo, designado como capitalismo conexionista, é, em uma palavra, o espírito da gestão. Trata-se da visão de mundo de um modo de exploração, dominação e socialização que foi capaz de incorporar a crítica às estruturas sociais rígidas e centralizadas, vinda das vertentes da crítica estética, em processos que permitiram, simultaneamente, enfraquecer e mesmo anular as vertentes de crítica política e suas concepções de equidade, bem comum e direitos coletivos.

A dominação de tipo gestionária do capitalismo conexionista (BOLTANSKI, 2013) está organicamente vinculada aos conhecimentos e instrumentos gerados no interior das ciências humanas e sociais. Ela opera, por um lado, pela instrumentalização social de uma ciência econômica que abstrai toda dimensão moral, com seus sistemas contábeis que selecionam e conferem significado à realidade em termos de necessidade: o realismo gestionário substitui a história como ferramenta para a formulação de narrativas abrangentes, oferecendo uma explicação causal no lugar de justificações morais e políticas. De outro lado, pelo uso intensivo das técnicas e ferramentas de gestão desenvolvidas nas grandes empresas e importadas para a esfera pública e política por diversas vertentes das ciências sociais (o chamado "novo paradigma da gestão pública"). Esses dispositivos de descrição e produção de realidade são essenciais para a dominação gestionária enquanto dominação sem sujeito, capaz de se reproduzir e expandir por meio de uma orquestração espontânea (BOURDIEU; BOLTANSKI, 2009). O espírito desse modo de dominação encarna-se em dispositivos e instituições que são apropriados de modo desigual pelos diversos membros de diferentes grupos sociais, segundo suas condições, disposições e estratégias, complicando a identificação dos que detêm as melhores condições relativas para acumular e monopolizar o poder de agir.

Um aspecto característico desse capitalismo é a conservação da ordem social pela produção incessante da mudança, gerando uma inquietação permanente que fomenta a adesão ativa dos indivíduos ao ideal da uma ação empreendedora contínua no mundo. Encontramos uma expressão exemplar dessa visão na substituição da concepção do trabalho como emprego 
e carreira pela ideia de competência, que suspende a distinção entre vida pessoal e profissional no planejamento e realização contínuos de uma sucessão de projetos. Assim, o novo espírito do capitalismo é o espírito, notadamente, da gestão de si mesmo, com o auxílio de amplo conjunto de saberes e técnicas especializados na produção de si como sujeito do desempenho (HAN, 2017). Seu objetivo central é maximizar a produção, notadamente a produção de si mesmo para o êxito em todas as esferas da vida. Característica marcante desse perfil ideal de indivíduo independente e livre para conquistar o mundo e o seu lugar no mundo é que ele não é obrigado a esse estilo de vida, marcado afinal pela busca intensa e incessante de êxito individual, por um poder externo, mas pela adesão profunda, pela incorporação das pressões sociais, pelas próprias exigências que se põem de superdesempenho e supercomunicação. Para ele, todo limite humano à produção, tal como o tempo de comer e de dormir, está aí para ser superado tecnicamente, em especial com o uso de substâncias químicas melhoradoras do desempenho individual que busca sua plenitude em um ideal de vida empreendedora e hiperconectada.

Um ponto que importa destacar aqui é que, da perspectiva da necessidade da produção incessante da mudança, os momentos de crise, seja ela econômica, política ou moral, funcionam como momentos de oportunidade para a expansão das intervenções gestionárias na realidade, ou seja, para a implementação de mais mudanças, por meio da criação e utilização de mais instituições e dispositivos de gestão e controle. Uma tal dinâmica baseia-se em visão peculiar da história: distinguindo-se de um conservadorismo retrógrado, o conservadorismo progressista recusa o passado e seus radicalismos, com base em um realismo evolucionista segundo o qual as mudanças sociais são expressão de uma evolução inexorável. Contudo, paradoxalmente, para que esse desenvolvimento necessário se efetive, é preciso uma ação intensa sobre o mundo. $\mathrm{O}$ futuro é inevitável, mas só acontecerá se todos se engajarem de corpo e alma em sua promoção. Desse modo a visão gestionária articula a linguagem da necessidade com a da vontade, do empenho e da coragem de fazer o que é necessário ser feito, a despeito dos males inevitáveis que o acompanham. A exigência de bravura e tenacidade do empreendedorismo requer igualmente a adesão ao conformismo de um realismo determinista que, identificando o provável ao possível, tem por efeito reduzir os sentidos concebíveis das possibilidades históricas (BOURDIEU; BOLTANSKI, 2009).

Por várias razões, a universidade ocupa lugar central nesse amplo quadro. Em seu aspecto mais visível, por conta da caracterização da ordem econômica vigente enquanto uma economia globalizada e baseada em conhecimento científico e tecnológico. Esse novo modo de conceber a valorização econômica do conhecimento e, consequentemente, da produção de produtores de conhecimento torna-se o pressuposto indiscutível das propostas que caracterizam 
o período, envolvendo as doutrinas sobre o novo modo de produção de conhecimento científico (por exemplo, GIBBONS et alii, 1999) que vão orientar as políticas de ciência, tecnologia e inovação (C\&T\&I) e seu novo paradigma da gestão pública, no âmbito do qual se inserem as reformas do perfil institucional e da organização do trabalho nas universidades, isto é, as reformas organizacionais.

Em pesquisa sobre as reformas organizacionais na universidade brasileira por meio do estudo de caso da concepção e implementação de um campus da USP na zona leste da cidade (a atual Escola de Artes, Ciências e Humanidades, EACH), foi possível acompanhar a influência da "teoria organizacional" nos projetos de reforma das universidades, fundamentado em uma literatura da sociologia das instituições que, desde a década de 1990 e ao longo dos anos 2000, tematiza o processo em termos de uma agenda globalizante de modernização das universidades que propõe uma completa redefinição das estruturas, normas e práticas acadêmicas nos termos de um ideal geral, altamente abstrato, de "organização" (GARCIA; CARLOTTO, 2012, 2013; CARLOTTO; GARCIA, 2018).

A "organização" apresenta-se como um conceito geral, capaz de descrever quase todas as formas institucionalizadas da atividade humana, em qualquer tempo e lugar. Da perspectiva dessa suposição abstrata, as mudanças acadêmicas atuais são processos quase-naturais de adaptação que vão promover, necessariamente, a eficiência técnica e social da instituição. Para isso, a universidade deve evoluir para a forma da organização moderna, eficiente e responsável, superando a forma da comunidade corporativa e ineficiente que se autogoverna visando atingir objetivos auto definidos.

Convertidas em organizações, na teoria ou na prática, as universidades são inseridas em um circuito transnacional de competição institucional, constituindo um campo organizacional das universidades (POWELL; DIMAGGIO, 1991) que vai orientá-las no sentido da criação de uma identidade institucional forte, que se define em referência às propriedades valorizadas no campo transnacional, que opera para além da interferência dos estados nacionais, assim como das profissões acadêmicas. Um componente fundamental da ideia de organização moderna aplicada à universidade é a responsabilidade institucional (accountability). Entre os processos que apontam nessa direção, pode-se ressaltar a crescente importância das certificações e dos rankings internacionais, a formalização das atividades de ensino e pesquisa e o desenvolvimento de técnicas e instrumentos de administração e coordenação desses processos.

Acompanhando esses movimentos com base no estudo dessas mudanças na USP, em especial, a concepção de responsabilidade social que vem orientando suas políticas de expansão de vagas e de cursos, pode-se observar um componente paradoxal da diretriz organizacional. 
Ele se refere à criação e notável expansão das instâncias centralizadas e hierarquizadas de coordenação e controle das decisões e das ações dos membros individuais da instituição. Esse aspecto explica a emergência da "onda da gestão" ("managerialism wave”), que se espraia por cima das profissões acadêmicas e do Estado nacional: a nova ênfase no nível organizacional abre espaço para que os gestores profissionais - suas visões, categorias, técnicas e instrumentos - ocupem os lugares da direção acadêmica, sendo, então, designados os dirigentes (MUSSELIN, 2006).

A análise do caráter paradoxal do projeto de modernização da universidade revela, então, seus efeitos de comprometimento da reprodução do perfil institucional que possibilitou o desenvolvimento histórico do pensamento racional na modernidade.

Quanto à especificidade institucional, a universidade, como organização, recusa e altera as estruturas e práticas acadêmicas que se vinculam à natureza específica de suas atividades e ao seu caráter historicamente enraizado. Não sendo possível estabelecer uma relação causal nítida entre tarefas específicas e resultados esperados, o trabalho intelectual apresenta resistência à formalização e segmentação em partes, por mais que se esforcem as escolas de administração para sistematizar as características e práticas que resultariam em criação produtiva. Na expressão de Cristine Musselin (2006), o ensino e a pesquisa configuram-se como "unclear technologies". Essa relativa independência intelectual, historicamente gerada e controlada por um tipo de concorrência que obriga às regras do diálogo metódico e da crítica racional generalizada (BOURDIEU, 2004), se expressa em sua característica institucional mais particular: ao contrário, por exemplo, das corporações empresariais, com seu objetivo único e incontestável, a universidade moderna distingue-se por incorporar objetivos variados e, inclusive, divergentes e concorrentes entre si (BEN-DAVID; ZLOCZOWER, 1962; SILVA, 1999). Trata-se, assim, de uma instituição que se define por sua capacidade de internalizar o conflito, notadamente, o conflito das faculdades, para usar o clássico termo de Kant (1993 [1798]), em sua argumentação dirigida ao poder político em defesa da liberdade da crítica racional na Faculdade de Filosofia.

No que se refere ao governo acadêmico, trata-se de uma instituição na qual, historicamente, estruturas formais de controle das práticas tiveram pouca eficácia e as tarefas administrativas foram geridas por corpos colegiados em formas descentralizadas de autogoverno, fazendo das universidades o exemplo mais claro das "anarquias organizadas", nas quais o governo interno distingue-se por formas fluidas de participação (COHEN et alii, 1972; KRÜCKEN; MEIER, 2006). 
Sinteticamente um recorte desse tipo para a investigação da universidade contemporânea permite, então, enxergar o caráter paradoxal constitutivo da visão de mundo dominante, em sua parcialidade. Compondo com as descrições intensamente disseminadas e crescentemente institucionalizadas do real em termos de redes, conexões, mobilidade, flexibilidade e plasticidade, descobre-se um modelo institucional que recupera e fortalece os arranjos centralizados e altamente hierarquizados de organização do trabalho, aqueles mesmos incansavelmente caracterizados, nas narrativas dominantes, a etapas superadas, desaparecidas, do capitalismo.

Ampliando o quadro para o mundo do trabalho em geral, vê-se que, na chave do sujeito do desempenho, da afirmação do esforço individual para a adaptação ao real inexorável, projeta-se o perfil tradicional do trabalho intelectual para todas as esferas de atividade social. Propõe-se, com muito entusiasmo, que todos os trabalhadores sejam enfim libertos das amarras das regras e das legislações trabalhistas, conquistando liberdade e autonomia para explorar insondáveis horizontes criativos, dependendo apenas de seu próprio empenho e talento. Mas, inversamente, para os trabalhadores intelectuais, os professores e pesquisadores universitários, adotam-se as práticas de tipo taylorista de organização e controle centralizado do trabalho que vão se associar, de formas muito complexas e algumas bastante tensas, com as práticas tradicionalmente baseadas na relativa independência do trabalho intelectual.

É com base na consideração do projeto gestionário como modelo puramente positivo da universidade, e com ela da ciência e da tecnologia, todas positivamente "a serviço da sociedade e da inovação", que o problema social do crescimento do transtorno e do adoecimento mental entre os jovens, e notadamente entre os jovens universitários, pode aparecer como irrupção da negatividade negada pelo padrão civilizacional dominante, como na reflexão do filósofo Byung-Chul Han (2017). Negatividade que emerge de um conflito que se desdobra no interior mesmo da subjetividade, que atormenta os corpos dos estudantes que, significativamente, são os que têm forçado a publicização do assunto (ainda muito silenciado no que se refere a funcionários e professores, incluindo os dirigentes), abrindo espaço para a reflexão do transtorno mental como sintoma social: a doença da época do capitalismo conexionista é a depressão.

Nos termos de Han, o "não posso mais" do deprimido na sociedade do "pode-se tudo porque tudo é possível" é a expressão da guerra cultural incorporada pelos indivíduos, embate no qual o ócio, o não fazer, a falha, atacam de dentro os ditames da vida hiperconectada. A negatividade, negada pelo padrão civilizacional dominante, que concebe toda a existência como pura positividade, se expressa, então, no âmbito da subjetividade, em especial daqueles que são 
convocados a realizar o ideal social: é no interior dos indivíduos superaquecidos pelo excesso de positividade que a violência da cultura contemporânea se manifesta. No registro da cultura dominante da civilização tecnológica, que só aceita alguma negatividade enquanto elemento da narrativa da trajetória do herói empreendedor de si mesmo (ou seja, o sofrimento só é válido se, no final, levar ao sucesso), a exaustão é inadmissível, ela é doença, transtorno e distúrbio em relação ao normal, ao saudável do indivíduo incansável, que tem diante de si um horizonte ilimitado de territórios a conquistar por sobre os escombros, inevitáveis, daqueles que fracassaram na tarefa inescapável de se adaptar ao necessário.

Pode-se, agora, voltar ao início, ao hoje do tema proposto para esta reflexão. Utilizando livremente os modelos de sistemas de dominação de Boltanski, seria possível dizer que estamos diante de dois sistemas de dominação que se justapõem na atualidade e que, por razões e de modos diferentes, ameaçam a continuidade histórica das instituições educacionais modernas. Teríamos, então, no Brasil (e em outros países que passam por processos similares promovidos pelo que já se designou de Internacional Conservadora) uma situação na qual se combinam um sistema de dominação pelo terror, baseado na opressão e na ameaça e uso da violência física, e um sistema de dominação gestionário, baseado na incitação à mudança constante e na violência simbólica. Trata-se de uma tipificação que não implica, por certo, que esses sistemas operem exclusivamente desses modos. O sistema gestionário do conservadorismo progressista não deixa de utilizar a violência física, mobilizando intensamente as forças policiais estatais, assim como o sistema do terror do novo conservadorismo baseia seu trabalho de cooptação no uso intensivo das mais avançadas tecnologias de informação e comunicação. Mas o ponto é que, nesse arranjo, a presença da ameaça do terror pode favorecer a adesão aos e o engajamento na expansão dos dispositivos que, segundo essa leitura, aprofundam a dominação de tipo gestionário, tirando potência de uma crítica radical das relações de apropriação, exploração e dominação que reproduzem e ampliam as desigualdades de diversas ordens. E desse modo, inversamente, os efeitos paradoxais da dominação gestionária poderão seguir favorecendo o cenário paradoxal de desequilíbrio, descontrole e insegurança da civilização tecnológica que abre espaço e convida para a submissão ao terror.

Mas não se pode concluir esta reflexão sem, ao menos, evocar as perspectivas emancipatórias ou democráticas que têm, hoje, que atuar nesse complexo cenário. Se as práticas não estão muito claras, confundidas pela apropriação de suas técnicas, tanto pelo sistema gestionário, em intenso trabalho simbólico, realizado ao longo de décadas, quanto pelo sistema do terror, em sua "guerra cultural" que associa doutrinas retrógradas e tecnologias de ponta, as diretrizes apresentam-se cada vez mais elaboradas, surgidas dos debates entre os movimentos 
sociais e o pensamento crítico. Sua linha geral, seu espírito, orienta-se para a realização histórica da democracia, entendida não apenas como regime político, mas também como estilo de vida, fundado na concepção do direito a ter direitos, concepção radical, intensamente atacada ao longo de sua história (RANCIÈRE, 2014), capaz de revelar o fundamento arbitrário, desprovido de razão, de toda sorte de dominação.

No âmbito da universidade, o espírito de emancipação desdobra-se em diversas dimensões, envolvendo o governo acadêmico, a organização do trabalho, o ensino, a pesquisa, a concepção de conhecimento racional e de sua relação com os saberes tradicionais, todas elas orientadas para a transformação da função social de reprodução e legitimação das desigualdades, desempenhada pelo sistema de ensino moderno desde sua invenção (ARIÉS, 1981; BOURDIEU, 1998; BOURDIEU; PASSERON, 2014). Nessa chave uma de suas maiores contribuições é a substancial complexificação do entendimento da dinâmica da dominação, pela articulação entre as relações de exploração constitutivas das classes sociais, as relações coloniais de apropriação de territórios e populações e seus recursos naturais e saberes e as relações de subordinação raciais e de gênero. Visão reveladora das arbitrariedades mais ocultas da história do capitalismo, ela parece ter potência para inventar ou redescobrir possibilidades encobertas pelo trabalho de dominação. Revelando a parcialidade dos diagnósticos tecnocráticos do fim da história e das visões retrógradas alinhadas a verdadeiro retrocesso civilizacional, as perspectivas emancipatórias atualizam o fato de que essa história ainda não terminou.

Agradecimentos

Agradeço a Mário Eufrásio e Ana Paula Hey pelo convite para compor a mesa $A$ educação no Brasil hoje e a Zeila Demartini, pelo convite para publicar esta contribuição nos Cadernos CERU.

\section{Referências bibliográficas}

ALEXANDER, Jeffrey. Vociferando contra o Iluminismo: a ideologia de Steve Bannon. Sociologia \& Antropologia, Rio de Janeiro, v. 8.3, p. 1009-23, set./dez. 2018.

ARIÈS, Philippe. História social da criança e da família. Rio de Janeiro: Zahar, 1981.

BEN-DAVID, Joseph; ZLOCZOWER, Awraham. Universities and academic systems in modern society. European Journal of Sociology, v. 3, p. 45-84, 1962.

BOLTANSKI, Luc; CHIAPELLO, Eve. O novo espírito do capitalismo. Trad. Ivone C. Benedetti. São Paulo: Martins Fontes, 2009.

BOLTANSKI, Luc. Sociologia da crítica, instituições e o novo modo de dominação gestionária. Trad. Philippe Dietman. Sociologia \& Antropologia, Rio de Janeiro, v. 3-6, p. 441-63, nov. 2013. 
BOURDIEU, Pierre; BOLTANSKI, Luc. La producción de la ideología dominante. Trad. Heber Cardoso. Buenos Aires: Nueva Vision, 2009.

BOURDIEU, Pierre; PASSERON, Jean-Claude. A reprodução. Elementos para uma teoria do sistema de ensino. Petrópolis, RJ: Vozes, 2014.

BOURDIEU, Pierre. A escola conservadora: as desigualdades frente à escola e à cultura. In: NOGUEIRA, M. Alice; CATANI, Afranio M. (Eds.). Escritos de educação. Petrópolis, RJ: Vozes, 1998. p. 39-64.

BOURDIEU, Pierre. Os usos sociais da ciência. Trad. Denice B. Catani. São Paulo: Unesp, 2004.

BOURDIEU, Pierre. Meditações pascalianas. Rio de Janeiro: Bertrand Brasil, 2007.

CARLOTTO, Maria C.; GARCIA, Sylvia G. Novos saberes, novas hierarquias. Disputas contemporâneas em torno da profissão acadêmica. Revista Brasileira de Ciências Sociais, v. 33, n. 96, 2018.

COHEN, Michael D. et alii. A garbage can model of organizational choice. Administrative Science Quarterly, v. 17, n. 1, p. 1-25, 1972.

GARCIA, Sylvia G.; CARLOTTO, Maria C. Institutional specificity and organizational change: A case of university social engagement in Brazil. In: PINHEIRO, R.; BENNEWORTH, P.; JONES, G. (Eds.). Universities and regional development: a critical assessment of tensions and contradictions. London \& New York: Routledge, Taylor and Francis, 2012. p. 124-40.

GARCIA, Sylvia G.; CARLOTTO, Maria C. Tensões e contradições do conceito de organização aplicado à universidade: o caso da criação da USP-Leste. Avaliação, v. 18, p. 657684, 2013.

GIBBONS, Michael et alii. The new production of knowledge. London: Sage, 1999.

HAN, Byung-Chul. Sociedade do cansaço. Trad. Enio Paulo Giachini. Petrópolis: Vozes, 2017.

KANT, Immanuel. O conflito das faculdades. Trad. Artur Morão. Lisboa: Edições 70, 1993.

KRÜCKEN, Georg; Meier, Frank. Turning the university into an organizational actor. In: DRORI, Gili S. et alii. (Eds.). Globalization and organization. Oxford: Oxford University Press, 2006. p. 241-257.

MUSSELIN, Christine. Are universities specific organizations? In: KRÜCKEN, Georg et alii. (Eds.). Towards a multiversity? Universities between global trends and national traditions. Bielefeld: Transcript Verlag, 2006. p. 63-84.

POWELL, Walter W.; DiMaggio, Paul J. (Eds.). The new institutionalism in organizational analysis. Chicago: The University of Chicago Press, 1991.

RANCIÈRE, Jacques. O ódio à democracia. São Paulo: Boitempo, 2014.

SILVA, Franklin Leopoldo e. A experiência universitária entre dois liberalismos. Tempo Social, São Paulo, v. 11, n. 1, p. 1-47, 1999. 